\title{
Vanishing viscosity limit of the 3D incompressible micropolar equations in a bounded domain
}

\author{
Yangyang $\mathrm{Chu}^{1}$ and Yuelong $\mathrm{Xiao}^{1}$ \\ ${ }^{1}$ Xiangtan University
}

October 30, 2021

\begin{abstract}
In this paper, we study the vanishing viscosity limit for the $3 \mathrm{D}$ incompressible micropolar equations in a flat domain with boundary conditions. We prove the existence of the global weak solution of the micropolar equations and obtain the uniform estimate of the strong solution. Furthermore, we establish the convergence rate from the solution of the micropolar equations to that of the ideal micropolar equations as all viscosities tend to zero (i.e., $(\varepsilon, \chi, \gamma, \chi)-0)$.
\end{abstract}

\section{Hosted file}

The 3D incompressible micropolar equations.pdf available at https://authorea.com/users/ 443694/articles/543642-vanishing-viscosity-limit-of-the-3d-incompressible-micropolarequations-in-a-bounded-domain

\section{Hosted file}

3D-micropolar equations.tex available at https://authorea.com/users/443694/articles/543642vanishing-viscosity-limit-of-the-3d-incompressible-micropolar-equations-in-a-boundeddomain 